\title{
Application of abscisic acid prevents leaf senescence at decreased irradiance
}

\author{
W. KUPIS ${ }^{1}$, E. TOMAL ${ }^{1}$, and E. NIEWIADOMSKA ${ }^{2 *}$ \\ Institute of Biology, Jan Kochanowski University, PL-25406 Kielce, Poland ${ }^{1}$ \\ The F. Górski Institute of Plant Physiology, Polish Academy of Sciences, PL-30239 Kraków, Poland ${ }^{2}$
}

\begin{abstract}
Several lines of evidence suggest that plant hormone abscisic acid (ABA) and the activity of alternative respiratory pathway are somehow interrelated. In this paper, we tested how an application of ABA affects the alternative oxidase (AOX) pathway and leaf senescence in Arabidopsis thaliana (L.) Heynh. Different effects of ABA application on the AOX activity were observed under high irradiance (HI) and low irradiance (LI). The expression of AOXID gene was stimulated, whereas the expression of senescence marker gene WRKY53 was decreased due to ABA treatment. We also noticed that changes of AOX genes $A O X 1 A$ and $A O X 1 D$, as well as AOX regulatory gene $A N A C 017$, were rather inversely correlated with irradiance-dependent changes in AOX activity. The expression of AOX1D and WRKY53 was diminished due to the application of $\mathrm{H}_{2} \mathrm{O}_{2}$ under LI. Our results are indicative that in some conditions an exogenous application of ABA may suppress leaf senescence. This action does not go via the induction of AOX activity, despite stimulation of AOX genes.
\end{abstract}

Additional key words: alternative respiratory pathway, Arabidopsis thaliana, reactive oxygen species.

Mitochondrial respiration provides the energy necessary to carry out various metabolic processes. The functioning of electron transport in the inner mitochondrial membrane generates proton gradient, which allows the ATP synthesis (Siedow and Umbach 1995). In addition to the classical cytochrome $c$ oxidase pathway, mitochondria of plants, algae, and some fungi contain the cyanideresistant alternative oxidase (AOX) pathway. AOX is an integral protein $(32-36 \mathrm{kDa})$ of the inner mitochondrial membrane, encoded by the nuclear genome (Rogov and Zvyagilskaya 2015). This enzyme is a part of the electron route from ubiquinone to oxygen, during which the gradient of $\mathrm{H}^{+}$across the mitochondrial membrane is not formed, hence the ATP production is significantly reduced. Instead, this pathway dissipates the energy mainly as heat (Vanlerberghe 2013).

The regulation of AOX activity in plants is carried out at the transcriptional and especially post-translational levels (Vanlerberghe and McIntosh 1997, Del-Saz et al. 2018). AOX is a protein that consists of the two monomers connected by cysteine disulfide "bridges", and changes in the type of its binding modify enzyme activity. The formation of intramolecular covalent bonds between the thiol cysteine groups in the AOX monomers after their oxidation leads to the enzyme inactivation, whereas the monomers connected by the non-covalent bond are active (Rogov et al. 2014). One of the candidates for redox activation of AOX is thioredoxin through modulation of AOX reduction state. The active protein (in its reduced form) can be regulated by $\alpha$-keto acids via interaction with cysteine residues leading to the changes in the protein conformation and increasing its activity. One of the most effective AOX activators at the low level of reduced ubiquinone is pyruvate. The

Submitted 28 June 2018, last revision 4 December 2018, accepted 5 December 2018.

Abbreviations: ABA - abscisic acid, AOX - alternative oxidase, CT - cycle threshold, CTAB - hexadecyl-trimethyl-ammonium bromide, EDTA - ethylenediaminetetraacetic acid, HI - high irradiance, LI - low irradiance, PVP - polyvinylpyrrolidone; ROS reactive oxygen species, SHAM - salicylhydroxamic acid, Tris-HCl - tris(hydroxymethyl)aminomethane hydrochloride.

Acknowledgements: The authors are thankful to prof. Jan Pałyga (UJK, Kielce, Poland) for critical comments on the manuscript.

* Corresponding author; e-mail: e.niewiadomska@ifr-pan.edu.pl 
availability of AOX substrates, such as a reduced fraction of the ubiquinone pool and oxygen pool, also affects the AOX activity (Del-Saz et al. 2018).

In Arabidopsis five AOX genes have been identified, named as $A O X 1 A, A O X 1 B, A O X 1 C, A O X 1 D$, and $A O X 2$. It has also been established that AOX is expressed in various plant organs and expression patterns may vary depending on the stage of development (Clifton et al. 2006). Long time ago, it has been recognized that AOX serves as a safety valve to decrease the generation of reactive oxygen species (ROS) in mitochondria (Maxwell et al. 1999). In Arabidopsis, the expression of this gene is induced by most types of abiotic stresses, including low temperature (Wang et al. 2012) and high irradiance (Zhang et al. 2010). Recent studies have demonstrated that $A O X 1 A$ plays a significant role in maintaining the redox status of the photosynthetic electron transport chain under high irradiance by preventing over-reduction of photosynthetic electron transport carriers (Vishwakarma et al. 2015). Furthermore, Zhang et al. (2016) have suggested that irradiance may affect chlorophyll synthesis during greening by the AOX-derived plastidial $\mathrm{NADPH} / \mathrm{NADP}^{+}$ratio change.

The stress conditions lead to changes in the hormonal homeostasis in plants and trigger the synthesis of stress hormone abscisic acid (ABA). The effects of ABA in plants are quite diverse. Both endogenous and exogenous ABA may promote leaf senescence (Finkelstein 2013). It is also important for acclimation to stresses and for the modulation of many developmental processes. The application of ABA increases the tolerance against low temperature and freezing, as shown with Arabidopsis plants and wheat callus (Dallaire et al. 1994, Mantyla et al. 1995, Preston and Sandve 2013). This may indicate the role of ABA in the preparation of plants for the winter season. The action of ABA influences hydrogen peroxide production, which in turn, affects resistance to stress, senescence, and cell death (Navabpour et al. 2003, Zimmermann and Zentgraf 2005, Lim et al. 2007). Also, an interplay between ABA and mitochondrial ROS production, modulated by $\mathrm{AOX}$, has been repeatedly shown (Huang et al. 2016). This suggests that both ABA and AOX pathways are somehow interrelated. Indeed, Yao et al. (2015) demonstrated that the expression of AOX was increased in the Arabidopsis plants treated with ABA.

The period of plant preparation for winter is characterized by reduced irradiance and increased ABA synthesis. This study was aimed to disclose the engagement of alternative respiratory pathway in this acclimation. For this reason, we mimicked the autumnal conditions by low irradiance and spraying plants with ABA and $\mathrm{H}_{2} \mathrm{O}_{2}$.

Arabidopsis thaliana L. (Columbia ecotype) plants were grown from seeds in sufficiently irrigated soil and in growth chambers with an irradiance of $250 \mu \mathrm{mol} \mathrm{m} \mathrm{m}^{-2} \mathrm{~s}^{-1}$ (denoted as HI), a 12-h photoperiod, day/night tempera- tures of $18 / 16^{\circ} \mathrm{C}$, and a relative humidity of $50 \%$. After reaching the stage of the fully developed rosette (after about 5 weeks) one set of plants was sprayed with 100 $\mu \mathrm{M}$ abscisic acid (denoted as HI ABA) dissolved in water, while the control plants were sprayed with water (HI C). These treatments were repeated 3 times each second day. Next, both sets of plants were transferred to low irradiance of $100 \mu \mathrm{mol} \mathrm{m} \mathrm{m}^{-2} \mathrm{~s}^{-1}$ (denoted as LI) and treated with water (LI C) or ABA (LI ABA) for the next $6 \mathrm{~d}$. Each set was composed of 12 plants. Later two additional plant sets of 6 plants each were grown. All growth conditions were the same like in the first experiment, but after transferring to LI one set of plants was sprayed with $20 \mathrm{mM} \mathrm{H} \mathrm{O}_{2}$ solution (named as LI $\mathrm{H}_{2} \mathrm{O}_{2}$ ) and another set was sprayed first with $20 \mathrm{mM}$ $\mathrm{H}_{2} \mathrm{O}_{2}$ and after $30 \mathrm{~min}$ with $100 \mu \mathrm{M}$ ABA (named as LI $\mathrm{H}+\mathrm{A}$ ). Again the treatment was repeated 3 times each second day. In all cases, the leaves were collected $2 \mathrm{~d}$ after last spraying and kept at $-80{ }^{\circ} \mathrm{C}$ for further analyses.

Calorimetric measurements were conducted on fresh A. thaliana leaves, collected $2 \mathrm{~d}$ after the last spraying, in the dark using a TAM III isothermal calorimeter equipped with TAM assistant software (Thermometric, Järfälla, Sweden). Fully developed leaves were collected from the middle part of the rosette ( 3 leaves per rosette, of about $0.02-0.03 \mathrm{~g}$ ) and divided into the 3 vials containing water, $0.1 \mathrm{~cm}^{3}$ of $1 \mathrm{mM} \mathrm{KCN}$ (an inhibitor of cytochrome oxidase) or $1 \mathrm{mM} \mathrm{KCN}+5 \mathrm{mM}$ salicylhydroxamic acid (SHAM; an AOX inhibitor). Each set of plants was composed of 5 - 6 plants. Heat emission was followed till the stable values were reached. To assess the portion of heat which accounts for the alternative respiratory pathway (AOX capacity) the combination of two inhibitors (KCN and SHAM) was used. This way was chosen to eliminate a possibility of reverse electron flow from the cytochrome $c$ and cytochrome $c$ oxidase to AOX. Total heat emission was calculated from the values measured in water. SHAM-sensitive heat emission, representing the AOX-dependent pathway, was derived from the difference between $\mathrm{KCN}$ and $\mathrm{KCN}+\mathrm{SHAM}$ treatments, as described previously (Niewiadomska et al. 2004). Heat emission was expressed in Watts (W).

Total RNA was isolated from $A$. thaliana leaves collected $2 \mathrm{~d}$ after the last spraying and ground in liquid nitrogen. Next, $0.7 \mathrm{~cm}^{3}$ of extraction buffer containing $2 \%(\mathrm{~m} / \mathrm{v})$ hexadecyl-trimethyl-ammonium bromide (CTAB), $2 \%(\mathrm{~m} / \mathrm{v})$ polyvinylpyrrolidone (PVP), $100 \mathrm{mM}$ Tris- $\mathrm{HCl}$ (pH 8.0), 25 mM EDTA, $2 \mathrm{M} \mathrm{NaCl}$ and $2 \%(\mathrm{v} / \mathrm{v}) \beta$-mercaptoethanol was added per $100 \mathrm{mg}$ of leaf powder. The suspension was incubated in $60{ }^{\circ} \mathrm{C}$ for $10 \mathrm{~min}$, centrifuged at $12000 \mathrm{~g}$ for $2.5 \mathrm{~min}$, and then an aqueous phase was transferred to a fresh tube and 0.7 $\mathrm{cm}^{3}$ of chloroform-isoamyl alcohol mixture (24:1) was added. After mixing for $20 \mathrm{~s}$ in vortex, the samples were centrifuged at $4000 \mathrm{~g}$ for $5 \mathrm{~min}$, the aqueous phase was transferred to a fresh tube and mixed with $1 / 3$ volume of 7.5 M lithium chloride solution. Samples were incubated 
for $1 \mathrm{~h}$ at $-72{ }^{\circ} \mathrm{C}$ and centrifuged at $10000 \mathrm{~g}$ and $4{ }^{\circ} \mathrm{C}$ for 20 min. A supernatant was discarded and a pellet was washed in absolute ethanol. The dried pellet was suspended in $0.05 \mathrm{~cm}^{3}$ of nuclease-free water. The concentration and purity of the nucleic acids were checked with a spectrophotometer (NanoDrop 2000 UV-Vis, Thermo Scientific, Waltham, MA, USA) and Bioanalyzer 2100 (Agilent Technologies, Santa Clara, CA, USA). Agarose gel electrophoresis was used to evaluate the integrity of the obtained samples. Each sample of total RNA was treated with DNase (DNA-free ${ }^{\mathrm{TM}}$ kit, Ambion, Carlsbad, CA, USA). The cDNA was obtained from $500 \mathrm{ng}$ of purified RNA by reverse transcription (iScript cDNA synthesis kit, BioRad, Hercules, CA, USA) with oligo(T) and random hexamers as the primers.

Transcription was assayed by real-time PCR (Eco Real-Time PCR System, Illumina, San Diego, CA, USA). The cDNA (50 ng) was amplified in the presence of $10 \mathrm{~mm}^{3}$ of qPCR mix (Maxim SYBR Green qPCR Master Mix (2X), Thermo Fisher Scientific, Waltham, MA, USA), $0.8 \mathrm{~mm}^{3}$ of $5 \mu \mathrm{M}$ specific primers (final concentration $0.2 \mu \mathrm{M}$ ) and $6.4 \mathrm{~mm}^{3}$ of nuclease-free water. PCR conditions were as follows: $50{ }^{\circ} \mathrm{C}$ for $2 \mathrm{~min}$, $95^{\circ} \mathrm{C}$ for $10 \mathrm{~min}, 35$ cycles of $95^{\circ} \mathrm{C}$ for $10 \mathrm{~s}$ followed by $60{ }^{\circ} \mathrm{C}$ for $1 \mathrm{~min}$. The primers used in the present study are listed in the Table 1 Suppl. Cycle threshold (CT) values were obtained from the exponential phase of PCR amplification. The comparative CT method was used to analyze the relative mRNA expression. In this method, the genes of interest were normalized against the expression of $A C T 2$ and $U B I 10$, used as reference genes.

One-way $A N O V A$ followed by Tukey's HSD multiple range test was performed using the Statistica12 software.

In order to mimic the conditions to which plants are exposed in autumn, we have grown the plants at HI and then transferred them to LI. Controls were grown at HI. Spraying with ABA solution was done both under HI and $\mathrm{LI}$, referring to the production of endogenous ABA. We noted a considerable change in the progression of senescence in LI plants but no visible symptoms of senescence were found in ABA-treated LI plants (Fig. 1 Suppl.)

The activity of alternative respiratory pathway was assessed by the emission of heat from leaf discs in darkness. This approach is based on earlier determinations made with Mesembryanthemum crystallinum plants demonstrating that both respiratory pathways stand for about $75 \%$ of the total heat emission from leaves (Niewiadomska et al. 2004). The total heat emission was similar in all four groups of plants [about $2000 \mu \mathrm{W} \mathrm{g} \mathrm{g}^{-1}$ (f.m.); Fig. 1A]. The values of SHAMsusceptible heat emission, corresponding to AOX capacity, are shown in Fig. $1 B$. Plant spraying with ABA under HI caused some increase in heat production. Whereas the transfer of plants from-HI-to-LI led to a significant decrease in SHAM-sensitive heat emission only in case of ABA-sprayed plants. Spraying with ABA under LI did not bring about any significant changes in heat production in comparison to LI treatment alone. Our results suggest that in the regulation of AOX capacity, the effect of irradiance is dominant over ABA.

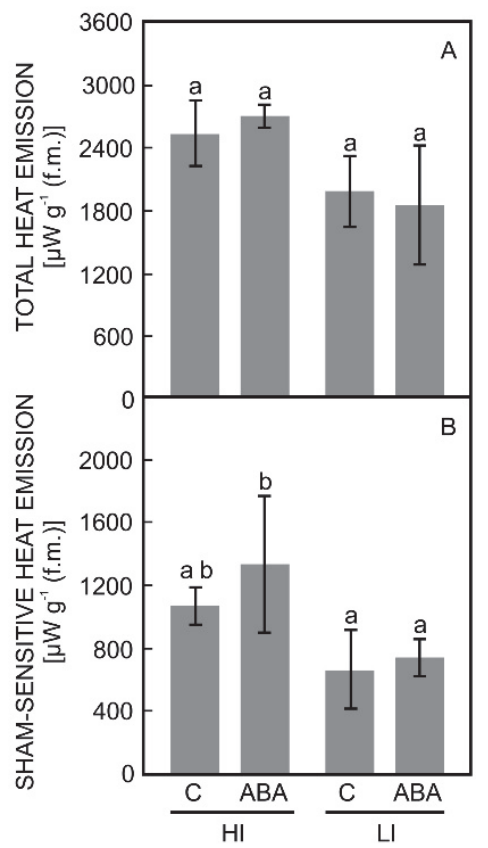

Fig. 1. Total heat emission in the dark $(A)$ and SHAM-sensitive heat emission $(B)$ determined in leaves collected from plants grown under high irradiance (HI C), grown at $\mathrm{HI}$ and sprayed with $\mathrm{ABA}$ (HI $\mathrm{ABA}$ ), grown at $\mathrm{HI}$ then transferred to low irradiance (LI C), and grown at $\mathrm{HI}$ then transferred to $\mathrm{LI}$ and sprayed with ABA (LI ABA). Means \pm SDs, $n=3$ or 4 . Different letters indicate statistically significant differences at $P \leq 0.05$ according to Tukey's test.

To verify whether the observed changes in the activity of AOX are reflected at the gene expression, we analyzed changes in the expression of two AOX genes, namely $A O X 1 A$ and $\mathrm{A} O X 1 D$, and also $A N A C 017$, a positive regulator of $A O X 1 A$ during mitochondrial dysfunction that mediated mitochondrial retrograde signalling $(\mathrm{Ng}$ et al. 2013, Van Aken et al. 2016). We also tried to analyze other AOX genes, namely $A O X 1 B, A O X 1 C$, and $A O X 2$, however, their expressions were too low, which was consistent with the results of Clifton et al. (2006). As a marker of senescence, we have chosen a senescenceassociated gene WRKY53. The expression of $A O X 1 A$ gene does not undergo significant changes due to LI or ABA treatment under HI, but some increase in expression was noted following ABA treatment under LI. The $A O X 1 D$ expression increased significantly after ABA treatment under both irradiances (HI+ABA and $\mathrm{LI}+\mathrm{ABA}$ ), while it was almost completely suppressed in the plants transferred from HI to LI. Changes in the expression of $A N A C 017$ gene were similar to those of $A O X 1 A$, with the lowest expression in $\mathrm{HI}+\mathrm{ABA}$ plants, 
and the highest in LI+ABA plants. In the case of WRKY53, a significantly reduced amount of transcripts was found after ABA treatments both under HI and LI, while the change in irradiance did not cause any significant alterations in comparison to HI control (Fig. 2).

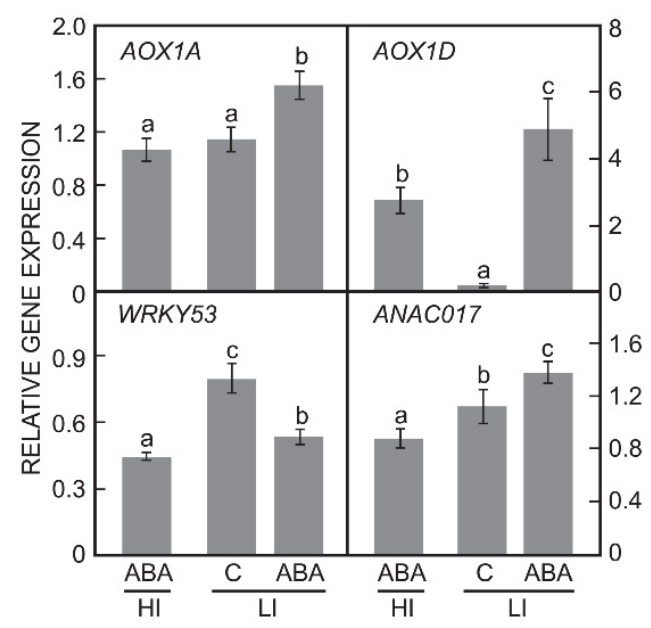

Fig. 2. Relative expression of genes $A O X 1 A, A O X 1 D, A N A C 017$, and WRKY53 in plants grown under high irradiance and sprayed with $\mathrm{ABA}$ (HI ABA), initially grown at HI then transferred to low irradiance (LI C), and initially grown at HI then transferred to LI and sprayed with ABA (LI ABA). The gene expressions were normalized to the expression of two reference genes $A C T 2$ and $U B I 10$ and calculated relative to values in control plants grown under HI set as 1 . Means \pm SDs, $n=6$. Different letters indicate significant differences at $P \leq 0.05$ according to Tukey's test.

Because ABA was shown to interact with ROS (Sah et al. 2016), in the next step, we analysed changes in gene expression caused by exogenously applied $\mathrm{H}_{2} \mathrm{O}_{2}$ to LI-grown plants with and without ABA treatment (Fig. 3). $\mathrm{H}_{2} \mathrm{O}_{2}$ treatment did not influence the expression of $A O X 1 A$ gene, but simultaneous treatment with $\mathrm{H}_{2} \mathrm{O}_{2}$ and $\mathrm{ABA}$ resulted in an increased $A O X 1 A$ expression. The reverse situation occurred when the expression of the $A O X 1 D$ was analysed. The expression of this gene was increased in both type of treatments, $\mathrm{H}_{2} \mathrm{O}_{2}$ and $\mathrm{H}_{2} \mathrm{O}_{2}$ $+\mathrm{ABA}$, but spraying with $\mathrm{H}_{2} \mathrm{O}_{2}$ alone caused a much higher stimulation. The expression of ANAC017 remained unchanged during both treatments. A slight decrease in the expression of WRKY53 was noted following $\mathrm{H}_{2} \mathrm{O}_{2}$ treatment only, and a much stronger decrease was found after simultaneous treatments with $\mathrm{H}_{2} \mathrm{O}_{2}$ and ABA.

In this paper, we tested whether an application of ABA in association with the changes in irradiance evoked any alterations in leaf senescence. Since ABA is a stress hormone associated with leaf abscission and dormancy (Finkelstein 2013), its action as a stimulator of leaf senescence might be expected. However, ABA is an important regulator of plant acclimation to various biotic and abiotic stresses (Yao et al. 2015). Transfer of plants from $\mathrm{HI}$ to LI induced visible symptoms of leaf senescence, whereas ABA treatment was capable to suppress this action. We suppose that the mechanism of senescence induction by HI-to-LI shift might be similar to that of dark-induced senescence. In the latter case, a strong decline in the capacity of mitochondrial activity was demonstrated in Arabidopsis rosettes after $6 \mathrm{~d}$ of darkening (Keech et al. 2007). Our data are in agreement with this pattern, however, a decline in respiratory activity due to LI (envisaged in our study by the total heat emission) was not that extreme as a decline in respiratory

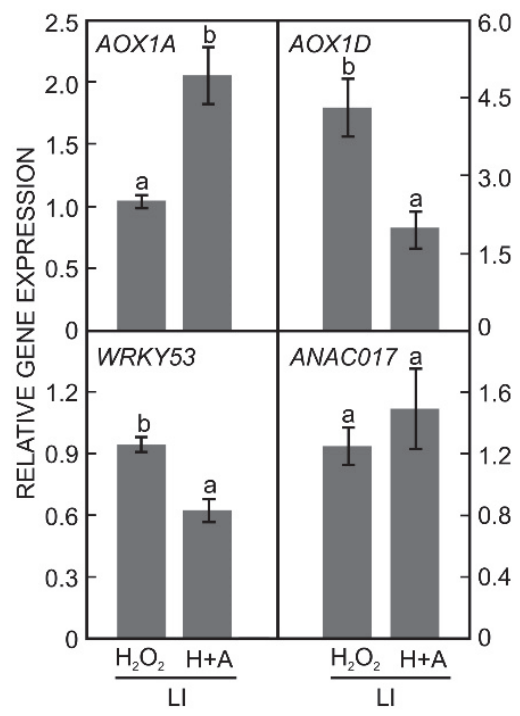

Fig. 3. Relative expression of genes $A O X 1 A, A O X 1 D$, $A N A C 017$, and WRKY53 in plants grown under low irradiance and sprayed with $\mathrm{H}_{2} \mathrm{O}_{2}\left(\mathrm{LI} \mathrm{H}_{2} \mathrm{O}_{2}\right)$ and plants grown under LI and sprayed with $\mathrm{H}_{2} \mathrm{O}_{2}$ and then with $\mathrm{ABA}(\mathrm{H}+\mathrm{A})$. The gene expression was normalized to the expression of two reference genes $A C T 2$ and $U B I 10$ and calculated relative to expression in control plants grown at LI. Means \pm SDs, $n=6$. Different letters indicate statistically significant differences at $P \leq 0.05$ according to Tukey's test. 
activity due to darkening of rosettes (represented by the number of mitochondria and by the rate of oxygen consumption with several respiratory substrates), as documented by Keech et al. (2007).

Next, we examined whether a delay in leaf senescence due to ABA might result from the activation of AOX pathway. Firstly, ROS are considered as a trigger of the senescence program (Zimmermann and Zentgraf 2005). Secondly, it is well documented that AOX dampens the generation of ROS and oxidative damage in mitochondria (Rhoads et al. 2006, Vanlerberghe 2013). Also, a protective role of AOX against programmed cell death has been shown (Vanlerberghe et al. 2002). Thirdly, the action of ABA is important for winter survival of some plants (Preston and Sandve 2013). As verified here, the activity of AOX was influenced predominantly by the irradiance and not by ABA. This effect might be explained by the involvement of alternative respiratory pathway in oxidation of excess reducing equivalents generated via the photosynthetic electron transport (Yoshida et al. 2007, Giraud et al. 2008). As concern gene expression, ABA stimulated $A O X 1 A$ and $A O X 1 D$ expression but this stimulation was rather weak in comparison to the reported data (Yao et al. 2015). The ABA signal is known to activate the mitochondrial retrograde regulation (MRR; Giraud et al. 2009, $\mathrm{Ng}$ et al. 2013, Yao et al. 2015), which in turn optimize the performance of plants in changing environment (Yao et al. 2015, Van Aken et al. 2016). The primary positive regulator of MRR, namely ANAC017, underwent some activation by LI, and more strongly by ABA. The latter corresponded well with the changes in $A O X 1 A$ expression. This is in agreement with the data documenting the activation of MRR and $A O X 1 A$ by

\section{References}

Clifton, R., Millar, A.H., Whelan, J.: Alternative oxidases in Arabidopsis: a comparative analysis of differential expression in the gene family provides new insights into function of non-phosphorylating bypasses. - Biochim. biophys. Acta 1757: 730-741, 2006.

Dallaire, S., Houde, M., Gagne, Y., Saini, H.S., Boileau, S., Chevrier, N., Sarhan, F.: ABA and low temperature induce freezing tolerance via distinct regulatory pathways in wheat. - Plant Cell Physiol. 35: 1-9, 1994.

Del-Saz, N.F., Ribas-Carbo, M., McDonald, A.E., Lambers, H., Fernie, A.R., Florez-Sarasa, I.: An in vivo perspective of the role(s) of the alternative oxidase pathway. - Trends Plant Sci. 23: 206-219, 2018.

Finkelstein, R.: Abscisic acid synthesis and response. Arabidopsis Book 11: e0166, 2013.

Giraud, E., Ho, L.H., Clifton, R., Carroll, A., Estavillo, G., Tan, Y.F., Howell, K.A., Ivanova, A., Pogson, B.J., Millar, A.H., Whelan, J.: The absence of ALTERNATIVE OXIDASE1A in Arabidopsis results in acute sensitivity to combined light and drought stress. - Plant Physiol. 147: 595-610, 2008.

Giraud, E., Van Aken, O., Ho, L.H., Whelan, J.: The application of ABA in Arabidopsis plants (Giraud et al. 2009, Yao et al. 2015).

Several reports have underpinned that ABA-signaling is closely linked with the action of ROS (Jammes et al. 2009, Kwak et al. 2013, Sah et al. 2016, Watkins et al. 2017). Therefore, to verify the modifying role of ROS in our experimental system we mimicked the action of $\mathrm{HI}$ by spraying the LI-grown plants with $\mathrm{H}_{2} \mathrm{O}_{2}$. This approach revealed that the expression of $A O X 1 A$ was stimulated solely by ABA and not by ROS. Although Ho et al. (2008) identified 10 cis-acting regulatory elements in the promoter region of Arabidopsis $A O X 1 A$ gene, and that $\mathrm{H}_{2} \mathrm{O}_{2}$ does also belong to its activators. In contrast to $A O X 1 A, A O X 1 D$ appeared to be stimulated by ROS under LI conditions. Although the differences in the expression of $A N A C 017$ were not significant between $\mathrm{H}_{2} \mathrm{O}_{2}$ and $\mathrm{H}+\mathrm{A}$ plants, its expression pattern was similar to that of $A O X 1 A$ and was slightly higher in the case of $\mathrm{H}+\mathrm{A}$ plants. This supports the observations of $\mathrm{Ng}$ et al. (2013) that $A N A C 017$ is a positive regulator of $A O X 1 A$ transcription and it is activated by ROS-produced in the mitochondria. Also Van Aken et al. (2016) found that ANAC017 regulates core mitochondrial retrograde responses. Though WRKY53 expression in Arabidopsis was found to be induced by $\mathrm{H}_{2} \mathrm{O}_{2}$ (Miao et al. 2004) our study showed that WRKY53 expression in $\mathrm{H}_{2} \mathrm{O}_{2}$-treated plants was restricted by ABA treatment, similarly to the effects evoked by the HI-LI change. These results bring evidence that ABA could act as an inhibitor of leaf senescence.

In this study we showed that an exogenous ABA may suppress leaf senescence. It seems that this action did not proceed via the induction of AOX activity, despite stimulation of AOX genes. transcription factor $\mathrm{ABI} 4$ is a regulator of mitochondrial retrograde expression of ALTERNATIVE OXIDASE1a. Plant Physiol. 150: 1286-1296, 2009.

Ho, L.H., Giraud, E., Uggalla, V., Lister, R., Clifton, R., Glen, A., Thirkettle-Watts, D., Van Aken, O., Whelan, J.: Identification of regulatory pathways controlling gene expression of stress-responsive mitochondrial proteins in Arabidopsis. - Plant Physiol. 147: 1858-1873, 2008.

Huang, S., Van Aken, O., Schwarzländer, M., Belt, K., Millar, A.H.: The roles of mitochondrial reactive oxygen species in cellular signaling and stress response in plants. - Plant Physiol. 171: 1551-1559, 2016.

Jammes, F., Song, C., Shin, D., Munemasa, S., Takeda, K., Gu, D., Cho, D., Lee, S., Giordo, R., Sritubtim, S., Leonhardt, N., Ellis, B.E., Murata, Y., Kwak, J.M.: MAP kinases $M P K 9$ and $M P K 12$ are preferentially expressed in guard cells and positively regulate ROS-mediated ABA signaling. - Proc. nat. Acad. Sci. USA 106: 20520-20525, 2009.

Keech. O., Pesquet, E., Ahad, A., Askne, A., Nordvall, D., Vodnala, S.M., Tuominen, H., Hurry, V., Dizengremel, P., Gardestrom, P.: The different fates of mitochondria and 
chloroplasts during dark-induced senescence in Arabidopsis leaves. - Plant Cell Environ. 30: 1523-1534, 2007.

Kwak, J.M., Mori, I.C., Pei, Z.M., Leonhardt, N., Torres, M.A., Dangl, J.L., Bloom, R.E., Bodde, S., Jones, J.D., Schroeder, J.I.: NADPH oxidase AtrbohD and AtrbohF genes function in ROS-dependent ABA signaling in Arabidopsis. - EMBO J. 22: 2623-2633, 2013.

Lim, P.O., Kim, H.J., Nam, H.G.: Leaf senescence. - Annu. Rev. Plant Biol. 58: 115-136, 2007.

Mantyla, E., Lang, V., Palva, E.T.: Role of abscisic acid in drought-induced freezing tolerance, cold acclimation, and accumulation of LT178 and RAB18 proteins in Arabidopsis thaliana. - Plant Physiol. 107: 141-148, 1995.

Maxwell, D.P., Wang, Y., McIntosh, L.: The alternative oxidase lowers mitochondrial reactive oxygen production in plant cells. - Proc. nat. Acad. Sci. USA 96: 8271-8276, 1999.

Miao, Y., Laun, T., Zimmermann, P., Zentgraf, U.: Targets of the WRKY53 transcription factor and its role during leaf senescence in Arabidopsis. - Plant mol. Biol. 55: 853-867, 2004.

Navabpour, S., Morris, K., Allen, R., Harrison, E., A-HMackerness, S., Buchanan-Wollaston, V.: Expression of senescence-enhanced genes in response to oxidative stress. J. exp. Bot. 54: 2285-2292, 2003.

Ng, S., Ivanova, A., Duncan, O., Law, S.R., Van Aken, O., De Clercq, I., Wang, Y., Carrie, C., Xu, L., Kmiec, B., Walker, H., Van Breusegem F., Whelan J., Giraud E.: A membranebound NAC transcription factor, ANAC017, mediates mitochondrial retrograde signaling in Arabidopsis. - Plant Cell 25: 3450-3471, 2013.

Niewiadomska, E., Karpinska, B., Romanowska, E., Slesak, I., Karpinski, S.: A Salinity-Induced C3-CAM transition increases energy conservation in the halophyte Mesembryanthemum crystallinum L. - Plant Cell Physiol. 45: 789-794, 2004.

Preston, J.C., Sandve, S.R.: Adaptation to seasonality and the winter freeze. - Front. Plant Sci. 4: 167, 2013.

Rhoads, D.M., Umbach, A.L., Subbaiah, C.C., Siedow, J.N.: Mitochondrial reactive oxygen species. contribution to oxidative stress and interorganellar signaling. - Plant Physiol. 141: 357-366, 2006.

Rogov, A.G., Sukhanova, E.I., Uralskaya, L.A., Aliverdieva, D.A., Zvyagilskaya, R.A.: Alternative oxidase: distribution, induction, properties, structure, regulation, and functions. Biochemistry (Moscow) 79: 1615-1634, 2014.

Rogov, A.G., Zvyagilskaya, R.A.: Physiological role of alternative oxidase (from yeasts to plants). - Biochemistry (Moscow) 80: 400-407, 2015.

Sah, S.K., Reddy, K.R., Li, J.: Abscisic acid and abiotic stress tolerance in crop plants. - Front. Plant Sci. 7: 571, 2016.

Siedow, J.N., Umbach, A.L.: Plant mitochondrial electron transfer and molecular biology. - Plant Cell 7: 821-831,
1995.

Van Aken, O., Ford, E., Lister, R., Huang, S., Millar, A.H.: Retrograde signalling caused by heritable mitochondrial dysfunction is partially mediated by ANAC 017 and improves plant performance. - Plant J. 88: 542-558, 2016.

Vanlerberghe, G.C.: Alternative oxidase: a mitochondrial respiratory pathway to maintain metabolic and signaling homeostasis during abiotic and biotic stress in plants. - Int. J. mol. Sci. 14: 6805-6847, 2013.

Vanlerberghe, G.C., McIntosh, L.: Alternative oxidase: from gene to function. - Annu. Rev. Plant Physiol. Plant mol. Biol. 48: 703-734, 1997.

Vanlerberghe G.C., Robson C.A., Yip, J.Y.H.: Induction of mitochondrial alternative oxidase in response to a cell signal pathway down-regulating the cytochrome pathway prevents programmed cell death. - Plant Physiol. 129: 1829-1842, 2002.

Vishwakarma, A., Tetali, S.D., Selinski, J., Scheibe, R., Padmasree, K.: Importance of the alternative oxidase (AOX) pathway in regulating cellular redox and ROS homeostasis to optimize photosynthesis during restriction of the cytochrome oxidase pathway in Arabidopsis thaliana. Ann. Bot .116: 555-569, 2015.

Wang, H., Huang, J., Liang, X., Bi, Y.: Involvement of hydrogen peroxide, calcium, and ethylene in the induction of the alternative pathway in chilling-stressed Arabidopsis callus. - Planta 235: 53-67, 2012.

Watkins, J.M., Chapman, J.M., Muday, G.K.: Abscisic acidinduced reactive oxygen species are modulated by flavonols to control stomata aperture. - Plant Physiol 175: 1807-1825, 2017.

Yao, X., Li, J., Liu, J., Liu, K.: An Arabidopsis mitochondrialocalized RRL protein mediates abscisic acid signal transduction through mitochondrial retrograde regulation involving ABI4. - J. exp. Bot. 66: 6431-6445, 2015.

Yoshida, K., Terashima, I., Noguchi, K.: Up-regulation of mitochondrial alternative oxidase concomitant with chloroplast over-reduction by excess light. - Plant Cell Physiol. 48: 606-614, 2007.

Zhang, D.W., Xu, F., Zhang, Z.W., Chen, Y.E., Du, J.B., Jia, S.D., Yuan, S., Lin, H.H.: Effects of light on cyanideresistant respiration and alternative oxidase function in Arabidopsis seedlings. - Plant Cell Environ. 33: 2121-2131, 2010.

Zhang, D.W., Yuan, S., Xu, F., Zhu, F., Yuan, M., Ye, H.X., Guo, H.Q., Lv, X., Yin, Y., Lin, H.H.: Light intensity affects chlorophyll synthesis during greening process by metabolite signal from mitochondrial alternative oxidase in Arabidopsis. - Plant Cell Environ. 39: 12-25, 2016.

Zimmermann, P., Zentgraf, U.: The correlation between oxidative stress and leaf senescence during plant development. - Cell. mol. Biol. Lett. 10: 515-534, 2005. 